\title{
Enhancing Effect of Carbohydrate Pyrolysates on Mutagenesis in Salmonella typhimurium
}

\author{
Hitoshi Окамото, Shigenobu Mizusaki, Daisuke Yoshida \\ and Takashi Matsumoto \\ Central Research Institute, The Japan Tobacco \& Salt Public Corporation, \\ 6-2 Umegaoka, Midori-ku, Yokohama, Kanagawa 227, Japan \\ Received December 1, 1978
}

\begin{abstract}
Carbohydrate pyrolysates obtained at $700^{\circ} \mathrm{C}$ intensively enhanced mutagenicities of several mutagenic agents on Salmonella typhimurium. The pyrolysates obtained by heating from 1 to $15 \mathrm{~min}$ had an enhancing effect on the mutagenicity of a similar level. Of the 8 kinds of carbohydrates tested, sucrose pyrolysate showed the highest enhancing effect. The enhancement of mutagenicity by sucrose pyrolysate was much more effective on aromatic amines such as 2 -aminofluorene and 2-aminoanthracene than on polycyclic aromatic hydrocarbons. The enhancing effect of sucrose pyrolysate was exhibited in the presence of a metabolic activation system.
\end{abstract}

Pyrolysates of protein and amino acids such as tryptophan and lysine have been reported to exhibit high mutagenicity against Salmonella typhimurium TA98..$^{(2)}$ Mizusaki et al..$^{(1)}$ have recently reported that mutagenicity of cigarette smoke condensate was due to protein and amino acids in tobacco shred during the smoking process and the mutagenic potency is dependent on the nitrogen and soluble-sugar contents of tobacco leaves. This prompted us to examine in detail interaction of pyrolysates of amino acids and sugars in exhibiting mutagenicity. The following interesting phenomena were observed in the course of this study. The pyrolytic product of a mixture of tryptophan and sucrose markedly decreased in mutagenicity on S. typhimurium TA98. On the contrary, when tryptophan pyrolysate was assayed simultaneously together with sucrose pyrolysate, the mutagenicity increased slightly. This paper describes the results concerning the enhancing effect of the sucrose pyrolysate on the mutagenicities

Abbreviations: DMSO, dimethylsulfoxide; AAF, 2-acetylaminofluorene; AF, 2-aminofluorene; AA, 2aminoanthracene; $\mathrm{BP}$, benzo(a)pyrene; $\mathrm{DAB}$, dimethylaminoazobenzene; 4-NQO, 4-nitroquinoline- $N$ oxide; $\mathrm{MNNG}, N$-methyl- $N^{\prime}$-nitro- $N$-nitrosoguanidine; PAH, polycyclic aromatic hydrocarbon; Trp-P, mutagenic fraction from tryptophan pyrolysate. of AAF, Trp-P and other chemicals.

\section{MATERIALS AND METHODS}

Chemicals. AAF, AF, AA, DAB, PAHs, benzo(f)quinoline, benzo(h)quinoline, 2-nitrofluorene, 4-NQO, MNNG, $\alpha$-nitronaphthalene and several carbohydrates were of the purest grade available from commercial sources. The Trp-P preparation was isolated from tryptophan pyrolysate ${ }^{5)}$ and consisted essentially of 3amino-1,4-dimethyl-5 $H$-pyrido-(4,3-b)-indole and 3amino-1-methyl-5H-pyrido-(4,3-b)-indole. ${ }^{b 3} \quad \alpha$-Amination of quinoline, isoquinoline, benzo(f)quinoline, benzo(h)quinoline and phenanthridine was carried out with sodium amide or potassium amide. ${ }^{7)} \quad N$-hydroxy$\mathrm{AF}^{8}$ ) and $N$-acetoxy-AAF ${ }^{\theta}$ ) were prepared by the methods cited in the references.

Method of pyrolysis. About $2.5 \mathrm{mg}$ of the sample was put into a small pyrex or quartz tube $(4 \mathrm{~mm}$ O.D. and $0.5 \mathrm{~mm}$ thick), which was evacuated to about $10^{-3} \mathrm{~mm} \mathrm{Hg}$ and sealed in a flame of commercial urban gas and oxygen. A pyrex tube was used in experiments lower than $600^{\circ} \mathrm{C}$ and a quartz tube was used in those higher than $700^{\circ} \mathrm{C}$. Pyrolyses were performed in a Packard Tri-carb Combustion Furnace, Model 325. The sealed tube was inserted into the middle of the pyrolysis column maintained at designated temperatures from 100 to $800^{\circ} \mathrm{C}$ and kept there for 1 to $15 \mathrm{~min}$. The tube after removal and cooling at room temperature was broken and $0.2 \mathrm{ml}$ of DMSO was added to the contents per $1 \mathrm{mg}$ of carbohydrate pyrolyzed. The DMSO solution was used for mutagenesis assay within $2 \mathrm{hr}$ after pyrolysis. 
Mutagenesis assay. Salmonella typhimurium test strains, TA98 and TA100, were kindly provided by Dr. B. N. Ames, University of California, Berkeley. The mutagenic testing was carried out as described by Ames et al. ${ }^{10)}$ To a test-tube containing $2 \mathrm{ml}$ of molten top agar $(0.6 \%$ agar, $0.6 \% \mathrm{NaCl}, 0.05 \mathrm{~mm}$ histidine, $0.05 \mathrm{~mm}$ biotin) were added $0.1 \mathrm{ml}$ of the DMSO solution of the pyrolysate, a proper amount of chemical solution $(0.1 \mathrm{ml}$ maximum), $0.1 \mathrm{ml}$ of an overnight nutrient broth culture of the bacterial test strain and $0.5 \mathrm{ml}$ of a solution that contained $0.05 \mathrm{ml}$ of rat liver microsomal fractions ( $\mathrm{S}-9), 4 \mu \mathrm{mol} \mathrm{MgCl}_{2}$, $33 \mu \mathrm{mol} \mathrm{KCl}, 2.5 \mu \mathrm{mol}$ glucose-6-phosphate $2 \mu \mathrm{mol}$, NADPH and $50 \mu \mathrm{mol}$ sodium phosphate buffer (pH 7.4). The tube contents were mixed and poured onto a plate containing $1.5 \%$ agar, $2 \%$ glucose and minimal salts. Histidine-revertant colonies were counted after incubation at $37^{\circ} \mathrm{C}$ for $48 \mathrm{hr}$. S-9 was obtained from rats induced with polychlorinated biphenyl as described by Ames et al. ${ }^{10}$ )

\section{RESULTS AND DISCUSSION}

The effect of sucrose pyrolysate on the mutagenicity of tryptophan pyrolysate on $S$. typhimurium TA98 is shown in Fig. 1. When tryptophan was pyrolyzed in the presence of sucrose, the mutagenicity of the pyrolytic product of the mixture decreased markedly with increasing amounts of sucrose in the

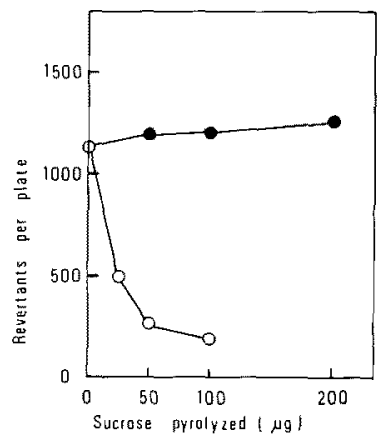

Fig. 1. Effect of Sucrose Pyrolysate on the Mutagenicity of Tryptophan Pyrolysate.

The pyrolyses were performed at $500^{\circ} \mathrm{C}$. Pyrolysates of a mixture of tryptophan and sucrose $(\mathrm{O}-\mathrm{O})$, and pyrolysates which were mixed after pyrolysis of tryptophan and sucrose separately (-) were tested for the mutagenicity using $S$. typhimurium TA98 in the presence of S-9 mix. The number of $\mathrm{His}^{+}$revertants per plate was plotted against amount of sucrose pyrolyzed. To each assay medium was added the pyrolysate from $50 \mu \mathrm{g}$ of tryptophan. pyrolysis. On the other hand, when tryptophan pyrolysate was assayed simultaneously

\section{Table I. Enhancing EfFect of Carbohydrate Pyrolysates on the Mutagenicity of AAF Toward S. typhimurium TA98}

Pyrolysate of $500 \mu \mathrm{g}$ carbohydrate, and $5 \mu \mathrm{g}$ of AAF was added to the assay mixture with $\mathbf{S}-9$ mix. The number of $\mathrm{His}^{+}$revertants of the each pyrolysate obtained at $700^{\circ} \mathrm{C}$ for $1 \mathrm{~min}$ was 70 on average. Non-pyrolyzed carbohydrates did not show any enhancing effect on the mutagenicity. Spontaneous revertants (55) were subtracted.

\begin{tabular}{llr} 
Sample & $\begin{array}{c}\text { Treatment } \\
\text { with pyrolysate } \\
\text { of carbohydrate }\end{array}$ & $\begin{array}{c}\text { Number of } \\
\text { revertants } \\
\text { per plate }\end{array}$ \\
\hline AAF & None & 259 \\
AAF & Glucose & 1304 \\
AAF & Fructose & 1427 \\
AAF & Mannose & 1237 \\
AAF & Ribose & 1388 \\
AAF & Sucrose & 1645 \\
AAF & Maltose & 1437 \\
AAF & Cellulose & 1359 \\
AAF & Sorbitol & 1122 \\
\hline
\end{tabular}

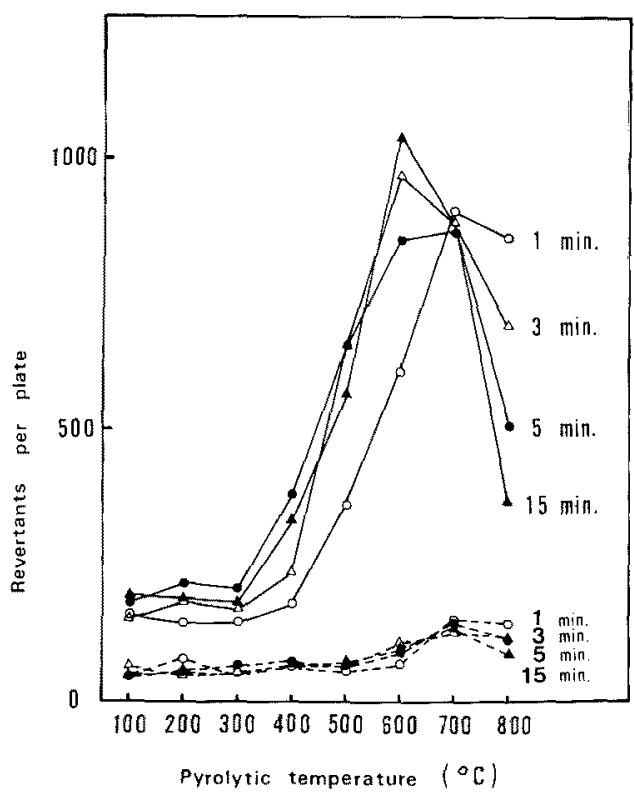

FIG. 2. Effect of Pyrolytic Temperature and Time on the Enhancement of Mutagenicity by Sucrose Pyrolysate.

Pyrolysate of $500 \mu \mathrm{g}$ sucrose with $(-$ ) or without (----) addition of $3 \mu \mathrm{g}$ AAF per plate was tested for mutagenicity using $S$. typhimurium TA98 in the presence of S-9 mix. 
together with sucrose pyrolysate, the mutagenicity of the mixture increased slightly. Addition of sucrose pyrolysate to mutagenic agents such as AAF and Trp-P also resulted in remarkable increases in the mutagenicities. In preliminary experiments, 8 kinds of carbohydrates including mono-, di- and polysaccharides were tested to determine their enhancing effects on the mutagenicity of AAF. As shown in Table I, all carbohydrates tested were found to enhance the mutagenicity and of them sucrose pyrolysate showed the highest enhancing effect. In the next experiment, sucrose was pyrolyzed at 8 different temperatures from 100 to $800^{\circ} \mathrm{C}$ for 1 to $15 \mathrm{~min}$. As shown in Fig. 2, the enhancing effect of sucrose pyrolysate on the mutagenicity of AAF was maximum when sucrose was pyrolyzed at 600 or $700^{\circ} \mathrm{C}$ and the highest activity changed little with pyrolytic time from 1 to $15 \mathrm{~min}$,

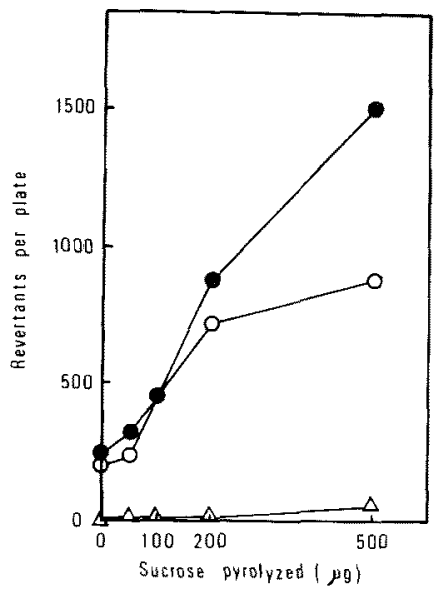

FIG. 3. Effect of the Doses of Sucrose Pyrolysate on the Enhancement of Mutagenicity.

Sucrose pyrolysates were tested for mutagenicity with $\mathrm{S}-9 \mathrm{mix}$ in the presence of $2 \mu \mathrm{g} \mathrm{AF}(--)$ ), or $0.1 \mu \mathrm{g}$ Trp-P $(O-O)$, or no addition $(\triangle-\triangle)$. Mutagenesis was assayed using TA98.
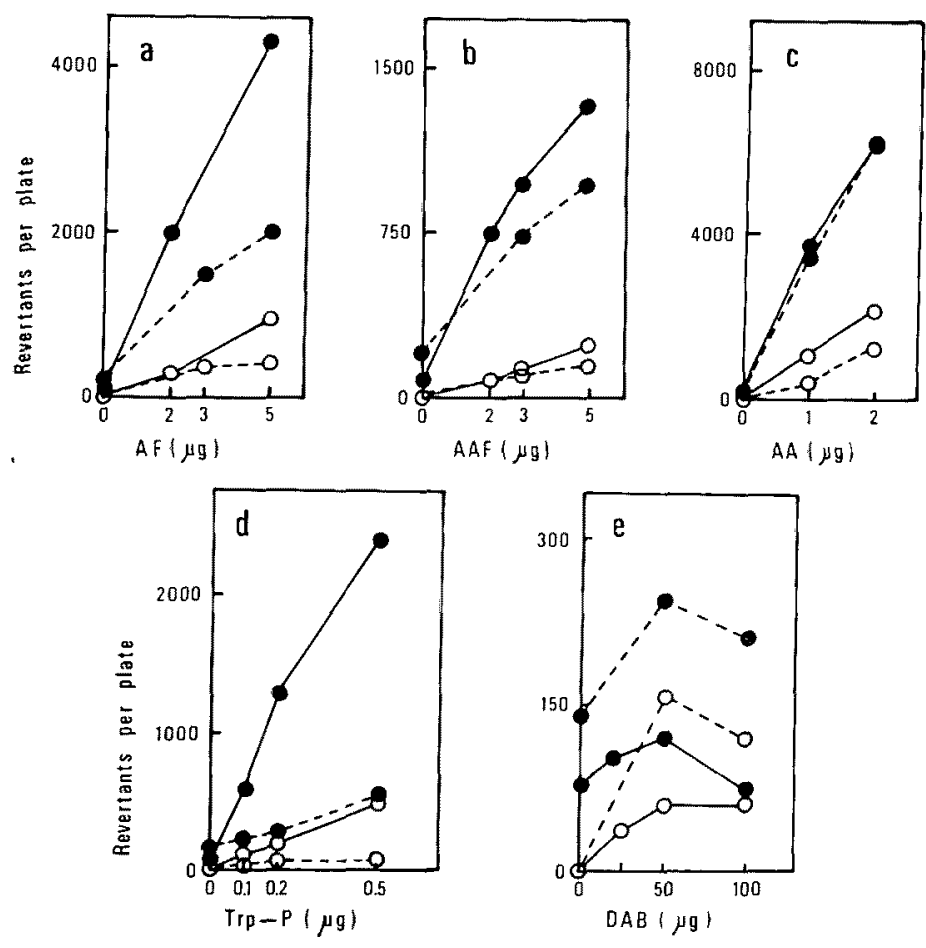

FIG. 4. Effect of the Dose of Chemicals on the Mutagenicity of Sucrose Pyrolysate.

Mutagenicities were tested using TA 98 and TA 100 with or without the pyrolysate corresponding to $500 \mu \mathrm{g}$ sucrose in the presence of S-9 mix. Mutagenicities of (a) AF, (b) AAF, (c) AA, (d) Trp-P and (e) DAB; with sucrose pyrolysate on TA $98(-\bullet)$, without sucrose pyrolysate on TA 98 $(\mathrm{O}-\mathrm{O})$, with sucrose pyrolysate on TA $100(\bullet--\bullet)$, without sucrose pyrolysate on TA $100(\mathrm{O}-\mathrm{O})$. 
Table II. Effect of Sucrose Pyrolysate on the Mutagenicities of Polycyclic Aromatic Hydrocarbons

The mutagenicities of PAHs were tested using S. typhimurium TA 98 and TA 100 with or without the pyrolysate corresponding to $500 \mu \mathrm{g}$ sucrose in the presence of S-9 mix. The number of spontaneous revertants (TA 98, 45; TA 100, 166) was subtracted.

\begin{tabular}{|c|c|c|c|c|c|c|}
\hline \multirow{3}{*}{ Compound } & \multicolumn{3}{|c|}{ TA 98} & \multicolumn{3}{|c|}{ TA 100} \\
\hline & \multirow{2}{*}{$\underset{(\mu \mathrm{g} / \text { plate })}{\text { Dose }}$} & \multicolumn{2}{|c|}{ Revertants per plate } & \multirow{2}{*}{$\begin{array}{c}\text { Dose } \\
\text { e) }(\mu \mathrm{g} / \text { plate })\end{array}$} & \multicolumn{2}{|c|}{ Revertants per plate } \\
\hline & & $\begin{array}{l}\text { without } \\
\text { SP }^{a}\end{array}$ & $\begin{array}{c}\text { with } \\
\mathrm{SP}^{a}(500 \mu \mathrm{g} / \text { plate })\end{array}$ & & $\begin{array}{l}\text { without } \\
\mathbf{S P}^{a}\end{array}$ & $\mathrm{SP}^{a}(500 \mu \mathrm{w} /$ plate $)$ \\
\hline Benzo(a)pyrene & 2 & 302 & 543 & 3 & 392 & 885 \\
\hline 3-Methylcholanthrene & 10 & 372 & 498 & 5 & 614 & 871 \\
\hline Anthracene & 100 & 16 & 92 & 100 & 88 & 228 \\
\hline Pyrene & 500 & 31 & 54 & 500 & 64 & 136 \\
\hline Chrysene & 10 & 47 & 99 & 5 & 310 & 720 \\
\hline Benz(a)anthracene & 20 & 119 & 191 & 5 & 148 & 354 \\
\hline Fluorene & 500 & N.D. ${ }^{b}$ & 15 & 500 & N.D. ${ }^{b}$ & 66 \\
\hline Phenanthrene & 500 & N.D. ${ }^{b}$ & 5 & 500 & 11 & 18 \\
\hline None & - & - & 82 & - & - & 140 \\
\hline
\end{tabular}

Table III. Effect of Sucrose Pyrolysate on the Mutagenicities of Quinoline Derivatives

The mutagenesis assay was performed using S. typhimurium TA 98 and TA 100 with or without the pyrolysate corresponding to $500 \mu \mathrm{g}$ sucrose in the presence of S-9 mix. The umber of spontaneous revertants (TA 98, 38; TA 100, 154) was subtracted.

\begin{tabular}{|c|c|c|c|c|c|c|}
\hline \multirow{3}{*}{ Compound } & \multicolumn{3}{|c|}{ TA 98} & \multicolumn{3}{|c|}{ TA 100} \\
\hline & \multirow{2}{*}{$\begin{array}{c}\text { Dose } \\
(\mu \mathrm{g} / \text { plate })\end{array}$} & \multicolumn{2}{|c|}{ Revertants per plate } & \multirow{2}{*}{$\begin{array}{c}\text { Dose } \\
(\mu \mathrm{g} / \text { plate })\end{array}$} & \multicolumn{2}{|c|}{ Revertants per plate } \\
\hline & & $\begin{array}{c}\text { without } \\
\mathrm{SP}^{a}\end{array}$ & $\mathrm{SP}^{a}(500 \mu \mathrm{g} /$ plate $)$ & & $\begin{array}{l}\text { without } \\
\mathrm{SP}^{a} \mathrm{SP}^{a}(500\end{array}$ & $\begin{array}{l}\text { with } \\
\mu \mathrm{g} / \text { plate) }\end{array}$ \\
\hline Quinoline & 100 & 98 & 87 & 50 & 566 & 497 \\
\hline 2-Aminoquinoline & 100 & 69 & 155 & 50 & 322 & 365 \\
\hline 1-Aminoisoquinoline & 200 & 16 & 65 & 200 & 74 & 236 \\
\hline Benzo(f)quinoline & 20 & 52 & 67 & 20 & 240 & 394 \\
\hline 2-Aminobenzo(f)quinoline & 1 & 241 & 1896 & 1 & 148 & 894 \\
\hline Benzo(h)quinoline & 100 & N.D. ${ }^{b}$ & 60 & 20 & 165 & 361 \\
\hline 2-Aminobenzo(h)quinoline & 20 & 58 & 114 & 1 & 149 & 445 \\
\hline 9-Aminophenanthridine & 20 & 100 & 162 & 20 & 289 & 461 \\
\hline None & - & - & 69 & $\ldots$ & - & 105 \\
\hline
\end{tabular}

${ }^{a}$ SP, sucrose pyrolysate; $\quad{ }^{b}$ N.D, not detected up to $500 \mu \mathrm{g}$.

whereas the pyrolysates of sucrose alone were very weakly mutagenic.

Fig. 3 shows the dose-response relationship of sucrose pyrolysate on the enhancing effect on the mutagenicities of AF and Trp-P toward TA98. The number of $\mathrm{His}^{+}$revertants induced by AF and Trp-P increased almost linearly with the dose level of sucrose pyrolysates added when they were assayed in the presence of S $-9 \mathrm{mix}$. The pyrolysate cor- responding to $500 \mu \mathrm{g}$ sucrose per tube enhanced the mutagenicities of AF and Trp-P several times. The enhancing effect of sucrose pyrolysate on the mutagenicities of several mutagenic agents on $S$. typhimurium TA98 and TA100 is shown in Fig. 4. The pyrolysate corresponding to $500 \mu \mathrm{g}$ sucrose was added to a tube of the assay mixture. The mutagenicities of AAF, AF, AA and Trp-P were markedly enhanced, but that of DAB was not 
so much. The numbers of $\mathrm{His}^{+}$revertants induced by AAF and Trp-P were increased 10 - and 8-fold in the presence of sucrose pyrolysate, respectively. Table II shows the effect of sucrose pyrolysate on the mutagenicities of PAHs on S. typhimurium TA98 and TA100. The enhancing effect of sucrose pyrolysate was evident in BP, 3-methylcholanthrene, chrysene and benz(a)anthracene on

\section{Table IV. Effect of Sucrose Pyrolysate on the Mutagenicity in the Absence OF S-9 Mix}

The mutagenicities were assayed with S.typhimurium TA98 and TA100 in the presence of the pyrolysate corresponding to $500 \mu \mathrm{g}$ sucrose. The number of spontaneous revertants (TA98, 71; TA100, 200) was subtracted.

\begin{tabular}{|c|c|c|c|}
\hline \multirow[b]{2}{*}{ Compound } & \multirow{2}{*}{$\begin{array}{c}\text { Dose } \\
(\mu \mathrm{g} / \text { plate })\end{array}$} & \multicolumn{2}{|c|}{ Revertants per plate } \\
\hline & & $\begin{array}{l}\text { without } \\
\qquad \mathrm{SP}^{a}\end{array}$ & $\begin{array}{c}\text { with } \\
\mathrm{SP}^{a} \\
(500 \mu \mathrm{g} / \mathrm{plate}\end{array}$ \\
\hline \multicolumn{4}{|l|}{ i) TA98 } \\
\hline 2-Nitrofluorene & 1 & 251 & 219 \\
\hline$N$-Hydroxy-AF & 0.5 & 3162 & 3214 \\
\hline$N$-Acetoxy-AAF & 5 & 100 & 114 \\
\hline None & - & - & 63 \\
\hline \multicolumn{4}{|l|}{ ii) $\mathrm{TA} 100$} \\
\hline 4-NQO & 1 & 3945 & 3829 \\
\hline MNNG & 2 & 1850 & 1864 \\
\hline$\alpha$-Nitronaphthalene & 50 & 1138 & 1186 \\
\hline None & - & - & 109 \\
\hline
\end{tabular}

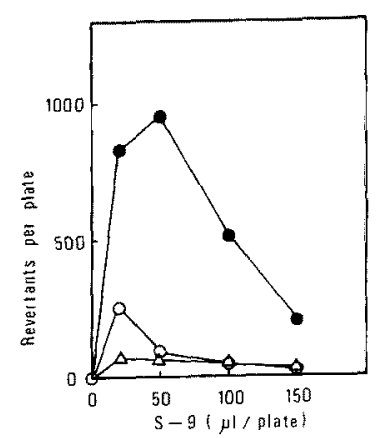

Frg. 5. Effect of Various Amounts of S-9 on the Mutagenicity of Sucrose Pyrolysate with AAF.

The mutagenesis test was performed using TA98 and pyrolysate of $500 \mu \mathrm{g}$ sucrose with $3 \mu \mathrm{g} \mathrm{AAF} \mathrm{(-)}$ or $3 \mu \mathrm{g}$ AAF $(\mathrm{O}-\mathrm{O})$ or pyrolysate of $500 \mu \mathrm{g}$ sucrose $(\Delta-\Delta)$.
TA100 and was not evident in anthracene, pyrene, fluorene and phenanthrene on both strains, but the effect on these compounds was much less than that on aromatic amines. The effect of sucrose pyrolysate on the mutagenicities of quinoline derivatives on TA98 and TA100 is shown in Table III. Of these compounds the most obvious enhancement of the mutagenicity was observed with 2-aminobenzo(f)quinoline.

The effect of sucrose pyrolysate on the mutagenicities of direct mutagens is shown in Table IV. Without S-9 mix, addition of sucrose pyrolysate did not show any enhancing effect on the mutagenicities of 2-nitrofluorene, $N$-hydroxy-AF and $N$-acetoxy-AAF against TA98 and on those of 4-NQO, MNNG and $\alpha$-nitronaphthalene against TA100. This clearly indicates that the enhancing effect of sucrose pyrolysate is exhibited in the presence of a metabolic activation system.

Next we examined the effect of different amounts of S-9 added on the enhancing action of sucrose pyrolysate with AAF on TA98. As shown in Fig. 5, the enhancing activity of sucrose pyrolysate with AAF increased up to $50 \mu \mathrm{l}$ of $\mathrm{S}-9$, and further increases in the amount of $S-9$ resulted in decreases in the number of revertants. However, without sucrose pyrolysate, the number of revertants of AAF was maxiumm at an amount of $20 \mu \mathrm{l}$ S-9, and with over $20 \mu$ the mutagenicity of AFF decreased. On the other hand, an increase in the amount of S-9 hardly affected the mutagenicity of sucrose pyrolysate.

Sucrose pyrolysate is very weakly mutagenic. However, in the case of aromatic amines the mutagenicity is much higher than expected from the sum of revertants induced by the mutagenic agents and those by surcose pyrolysate. Matsumoto et al. ${ }^{111}$ and Nagao et al. ${ }^{12 \sim 14)}$ recently reported that harman and norharman, which were not mutagenic, showed comutagenic actions to Trp-P, BP, DAB, aniline and other several chemicals in the presence of S-9 mix. More recently, Umezawa et $a{ }^{151}{ }^{15}$ reported that, in the absence of $\mathrm{S}-9$ mix, the mutagenicity of $N$-acetoxy-AAF was 
greatly increased by addition of norharman or harman. In our experiment, sucrose pyrolysate had no remarkable enhancing effect on the mutagenicities of $\mathrm{DAB}$ and PAHs with S-9 mix and $N$-acetoxy-AAF without S-9 mix. These facts suggest that the mechanism for exhibiting the enhancing effect of sucrose pyrolysate on the mutagenicity is different from that of norharman and harman.

The presence of S-9 mix is essential for the enhancing action of sucrose pyrolysate, suggesting that interaction between the metabolic process of a mutagen and that of sucrose pyrolysate may occur.

Purification of the principle(s) which cause(s) the enhancing effect is underway in our laboratory.

Acknowledgments. The authors thank Drs. F. Goto, K. Tomaru and A. Koiwai, of this Institute, for helpful discussions and comments on the manuscript. We also thank Miss A. Akiyama and Miss Y. Fukuhara for assistance with the assays.

\section{REFERENCES}

1) T. Matsumoto, D. Yoshida, S. Mizusaki and H. Okamoto, Mutation Res., 48, 279 (1977).

2) T. Matsumoto, D. Yoshida, S. Mizusaki and H. Okamoto, Mutation Res., 56, 281 (1978).

3) M. Nagao, M. Honda, Y. Seino, T. Yahagi, T. Kawachi and T. Sugimura, Cancer Letters, 2, 335
(1977).

4) S. Mizusaki, H. Okamoto, A. Akiyama and Y. Fukuhara, Mutation Res., 48, 319 (1977).

5) D. Yoshida, T. Matsumoto, R. Yoshimura and T. Matsuzaki, Biochem. Biophys. Res. Commun., 83, 915 (1978).

6) T. Sugimura, T. Kawachi, M. Nagao, T. Yahagi, Y. Seino, T. Okamoto, K. Shudo, T. Kosuge, K. Tsuji, K. Wakabayashi, Y. litaka and A. Itai, Proc. Japan Acad., 53, 58 (1977).

7) T. Matsumoto, D. Yoshida, S. Mizusaki, H. Tomita and K. Koshimizu, Agric. Biol. Chem., 42, 861 (1978).

8) L. A. Poirier, J. A. Miller and E. C. Miller, Cancer Res., 23, 790 (1963).

9) P. D. Lotlikar, J. D. Scribner, J. A. Miller and E. C. Miller, Life Sci., 5, 1263 (1966).

10) B. N. Ames, J. McCann and E. Yamasaki, Mutation Res., 31, 347 (1975).

11) T. Matsumoto, D. Yoshida and S. Mizusaki, Mutation Res., 56, 85 (1977).

12) M. Nagao, T. Yahagi, M. Honda, Y. Seino, T. Matsushima and T. Sugimura, Proc. Japan Acad, 53, Ser. B, 34 (1977).

13) M. Nagao, T. Yahagi, T. Kawachi, T. Sugimura, T. Kosuge, K. Tsuji, K. Wakabayashi, S. Mizusaki and T. Matsumoto, Proc. Japan Acad., 53, 95 (1977).

14) M. Nagao, M. Honda, T. Yahagi, Y. Seino, T. Kawachi and T. Sugimura, Cancer Letters, 3, 339 (1977).

15) K. Umezawa, A. Shirai, T. Matsushima and T. Sugimura, Proc. Natl. Acad. Sci. U.S.A., 75, 928 (1978). 